\title{
Acute Migraine Prescription Patterns Vary by Baseline Cardiovascular Risk and Clinical Characteristics: A Real-World Evidence Study
}

\author{
$\mathrm{Hu}$ Li · Maurice Vincent · Xiang Zhang · Ellen B. Dennehy • \\ Robert Goodloe · Sheena K. Aurora · Timothy R. Smith
}

Received: February 12, 2020 / Published online: April 23, 2020

(C) The Author(s) 2020

\begin{abstract}
Introduction: Migraine is a debilitating neurological disease and one of the most common disorders in the world. Although the triptans, potent $5-\mathrm{HT} 1 \mathrm{~B} / 1 \mathrm{D}$ receptor agonists, are an effective and widely used acute treatment of migraine, few studies have assessed how their cardiovascular risk warnings could impact prescription patterns. This study characterized cardiovascular risk factors and other aspects of people with migraine in real-world settings and confirmed patterns of acute migraine care.

Methods: This retrospective study included five cohorts: people with migraine prescribed acute treatments [triptans, opiates, prescription
\end{abstract}

Enhanced Digital Features To view enhanced digital features for this article go to https://doi.org/10.6084/m9. figshare.12047256.

H. Li $(\bowtie) \cdot$ M. Vincent · X. Zhang ·

E. B. Dennehy · R. Goodloe · S. K. Aurora

Eli Lilly and Company, Lilly Corporate Center, Indianapolis, IN, USA

e-mail: li_hu_hl@lilly.com

\section{E. B. Dennehy}

Department of Psychological Sciences, Purdue

University, West Lafayette, IN, USA

T. R. Smith

StudyMetrix Research, St Peters, MO, USA nonsteroidal anti-inflammatory drugs (NSAIDs)], untreated people with migraine, and individuals without migraine diagnosis. Baseline demographic and clinical characteristics were used to develop and validate a 1-year myocardial infarction (MI) risk prediction model among untreated people with migraine. This validated prediction model generated disease risk scores (DRSs) for MI among untreated cohorts.

Results: Patients in the study included 436,642 prescribed a triptan, 55,234 prescribed opiates, and 334,152 prescribed NSAIDs; as well as $1,168,212$ untreated persons with migraine and $11,735,009$ nonmigraine participants. Those prescribed triptans were younger, had fewer cardiovascular risk factors and hospitalizations, and lower concomitant medication use than those in the NSAID and opiate cohorts. The distribution of the DRS showed that compared to patients prescribed NSAIDs (4.2\%) or opiates $(3.5 \%)$, a smaller proportion of patients prescribed triptans (1.3\%) were at high risk for MI at 1 year $(>10 \%)$.

Conclusion: People with migraine who had more cardiovascular risk factors and greater 1-year MI risk score were disproportionately prescribed opiates and NSAIDs compared to triptans. Future research should explore unmet needs for patients with disorders for which triptan therapy is contraindicated. 
Keywords: Acute care; Cardiovascular diseases; Demography; Hypertension; Migraine disorders; Myocardial infarction; Non-steroidal antiinflammatory drugs; Opioid analgesics; Risk factors; Triptans

\section{Key Summary Points}

Why carry out this study?

Although triptans are widely used for the acute treatment of migraine, they induce vasoconstriction and are contraindicated in patients with cardiovascular disease (CVD); consequently, patients with migraine who are at greater risk of CVD are less likely to be prescribed triptans.

We hypothesized that patients prescribed fewer triptans in clinical practice have a higher rate of cardiovascular risk factors than those receiving opiates or prescription nonsteroidal antiinflammatory drugs (NSAIDs).

\section{What was learned from the study?}

Triptan-prescribed patients were found to be healthier with fewer baseline hospitalizations and cardiovascular risk factors (e.g. hypertension, diabetes, hyperlipidemia).

Patients with migraine who had more cardiovascular risk factors and a higher 1-year myocardial infarction risk were more likely to be prescribed opiates and NSAIDs in comparison to triptans.

There is clear unmet need in patients with migraine and conditions for which triptan therapy is contraindicated.

\section{INTRODUCTION}

Migraine is a debilitating neurological disease with an estimated global prevalence of $11.6 \%$ (approximately 1 billion persons), making it one of the most common disorders in the world [1]. Migraine, in general, and specifically migraine with aura have been associated with an up to twofold increased risk of ischemic stroke [2-4]. A similar association has been found between migraine and cardiovascular events [5]. Women with migraine, compared to those without migraine, have an elevated risk of myocardial infarction (MI), angina, or coronary revascularization and of cardiovascular mortality [5], with their relative risk for major cardiovascular disease (CVD) being roughly 50\% higher than that of women without migraine, regardless of age.

Triptans are widely used for the acute treatment of migraine, with strong evidence supporting their efficacy [6, 7]; however, triptans induce vasoconstriction [8]. All U.S. triptan labels indicate that triptans are contraindicated in patients with CVD and warn patients with pre-existing CVD not to use them [9]. For example, the package insert for sumatriptan tablets [10] states that this medication is contraindicated in individuals with a history of coronary artery disease or coronary artery vasospasm, history of stroke, transient ischemic attack or hemiplegic or basilar migraine, uncontrolled hypertension, or ischemic bowel disease. As a result, patients with migraine who are at greater risk of CVD are less likely to be prescribed triptans [11].

To date, few comparative observational studies have investigated the treatment patterns of migraine-specific drugs in real-world clinical practice. In fact, a systematic review only identified four relevant observational studies (3 nested case-control analyses and 1 retrospective cohort study) examining this question [8]. However, the authors of the review concluded that based on the small number of trials as well as the different study designs, triptans, and outcome measures of these trials, it was not possible to draw any firm conclusions about cardiovascular safety.

The objectives of this study were to characterize the distribution of cardiovascular risk factors, baseline demographics, and other clinical characteristics among individuals with migraine in real-world settings and to describe patterns of acute migraine care in those with 
varying degrees of cardiovascular risk. Such data may help to provide additional clinical information regarding the treatment of acute migraine. We hypothesized that, due to the labeled contraindications of triptans, patients prescribed triptans in clinical practice have a lower rate of cardiovascular risk factors than those receiving opiates or prescription nonsteroidal anti-inflammatory drugs (NSAIDs).

\section{METHODS}

\section{Ethics}

This article is based on a retrospective analysis of de-identified patient data from the U.S. healthcare system, and does not contain any studies with human participants or animals performed by any of the authors.

\section{Data Sources}

The use of data from the IBM ${ }^{\circledR}$ MarketScan ${ }^{\circledR}$ Research Databases was licensed from IBM ${ }^{\circledR}$ Watson Health ${ }^{\mathrm{TM}}$ (IBM Corp., Armonk, NY, USA) for research purposes. The MarketScan Databases contain de-identified healthcare claims information from employers, health plans, hospitals, Medicare, and Medicaid programs. The MarketScan Databases were created in 1995 and are currently one of the largest collections of de-identified patient-level data in the USA. They reflect the real world of treatment patterns and costs by tracking millions of patients as they navigate the healthcare system and provide detailed information about all aspects of care. These databases are fully Health Insurance Portability and Accountability Act (HIPAA) compliant. In 2017, the MarketScan Databases contained data for more than 43.6 million covered lives.

\section{Study Population and Study Design}

The study population included patients aged $\geq 18$ years listed in the MarketScan Databases who, during the study period of January 2004 to December 2016, had at least 12 months of continuous enrollment in a health plan prior to the index date. Patients diagnosed with cluster headache were excluded from the study.

A retrospective cohort study design was used to compare outcomes between patients with migraine exposed to triptans versus prescription opiates, triptans versus prescription NSAIDs, and prescription NSAIDs versus prescription opiates. The index date was defined as the first diagnosis of migraine or first prescription of acute treatment for migraine medications or randomly selected clinical visit for general nonmigraine patients.

The baseline period was defined as the 12 months prior to the index date. Baseline characteristics ascertained during this period included demographics, utilization measures, and concomitant medication use as well as all cardiovascular risk factors that were measurable in the data source.

\section{Cohort Formation}

The study cohorts include three active migraine-treated cohorts (triptan, prescription NSAID, and opiate cohorts), a cohort of patients with migraine not actively treated with those acute medications (untreated migraine cohort), and a cohort of patients without migraine diagnosis (general nonmigraine cohort). Patients in the triptan, opiate, and NSAID cohorts were identified within the database as those with migraine who received $\geq 1$ prescription of a triptan, opiate, or NSAID, respectively. Patients received an initial "new" prescription of the respective cohort medication (triptan, NSAID, or opiate) and were not exposed to any of the study medications prior to the index date. Patients in any of the three active migraine-treated cohorts could switch to a different treatment during follow-up, but they were removed from the study cohort at the initiation of treatment with the other anti-migraine medicines. In addition, patients were not diagnosed with any other chronic pain indications (osteoarthritis, rheumatoid arthritis, chronic pain, and/or injury, trauma hospitalization $>3$ days). The identification of patients in the other cohorts was similar. 
In each case, patients were identified within the database as those with migraine who received $\geq 1$ prescription of NSAIDs (NSAID group) or opiates (opiate group). Diagnosis of migraine was required within 30 days prior to the first prescription, patients with other chronic pain indications (osteoarthritis, rheumatoid arthritis, chronic pain, and/or injury or trauma hospitalization $>3$ days) were excluded, and patients were not exposed to any study prescription medications prior to the index date. Patients in the untreated migraine cohort were identified within the database as subjects who had a diagnosis of migraine but had no prior prescription for any acute treatment of migraine. Patients with untreated migraine who initiated a new anti-migraine medication at a later time were eligible for the untreated migraine cohort until the time the new treatment was initiated.

Lastly, the general nonmigraine cohort contained two types of patients; those who never received a diagnosis of or treatment for migraine, and those who were participants of the general nonmigraine cohort until the time of diagnosis and/or first prescription. Individuals in the general nonmigraine cohort were matched to patients in the untreated migraine cohort with a 1:4 ratio based on age and sex. The index date was a randomly selected clinical visit within a 3-month window when the patient was matched.

\section{Disease Risk Score Development}

The disease risk score (DRS) characterizes a person's likelihood of disease occurrence. The DRS is based upon subsets of covariates that reflect underlying risk factors and reduces the dimensionality of covariates to a single disease prediction score, in this case, for ischemic cardiovascular outcomes as measured by the occurrence of MI at 1-year post index. A cardiovascular DRS was generated and validated using a prediction model. The dataset was randomly split into training and validation datasets, and the split was replicated 100 times. The prediction model was applied 100 times using training datasets and 100 times using validation datasets to evaluate the performance of the model fitting. No formal statistical analyses were performed to test the difference across groups.

Univariate regression was applied to all patients in the untreated migraine cohort to select factors strongly associated with MI, and those factors were included in a multivariate regression for further assessment $(P<0.05)$. Multivariate regression was subsequently applied. Stepwise selection was implemented to select factors strongly associated with the outcome, while accounting for possible correlation between those factors. Additional predictors were considered based on clinical relevance. Predictors were chosen based on statistical significance and clinical relevance.

\section{RESULTS}

Data for 223,023,828 patients at least 18 years of age were available in the MarketScan Databases from January 2005 to December 2016. The selection of the study population is summarized in Fig. 1. Five cohorts were formed: triptan $(N=436,642), \quad$ prescription NSAID $(N=334,152)$, opiate $(N=55,234)$, untreated migraine $(N=1,168,212)$, and nonmigraine $(N=11,735,009)$.

Baseline demographic data for each of the cohorts are presented in Table 1. Patients in the triptan cohort were numerically younger $(37.7 \pm 12.4$ years $)$ than those in the general nonmigraine cohort ( $45.7 \pm 17.4$ years), NSAID cohort (39.4 \pm 14.0 years), opiate cohort $(39.7 \pm 13.4$ years $)$, and untreated migraine cohort $(41.0 \pm 14.6$ years) (all data are the mean \pm standard deviation). In addition, compared to patients in the other cohort groups, patients in the triptan cohort had fewer baseline hospitalizations in the last 30 days $(0.4 \%$, compared to $8.1 \%$ in the NSAID cohort, $13.8 \%$ in the opiate cohort, and $1.0 \%$ in the untreated migraine cohort) and in the last 31-365 days (2.5\%, compared to $4.0 \%$ in the NSAID cohort, $4.3 \%$ in the opiate cohort, and $3.9 \%$ in the untreated migraine cohort). For comparison, $0.3 \%$ and $2.9 \%$ of patients in the general nonmigraine cohort had hospitalizations in the last 


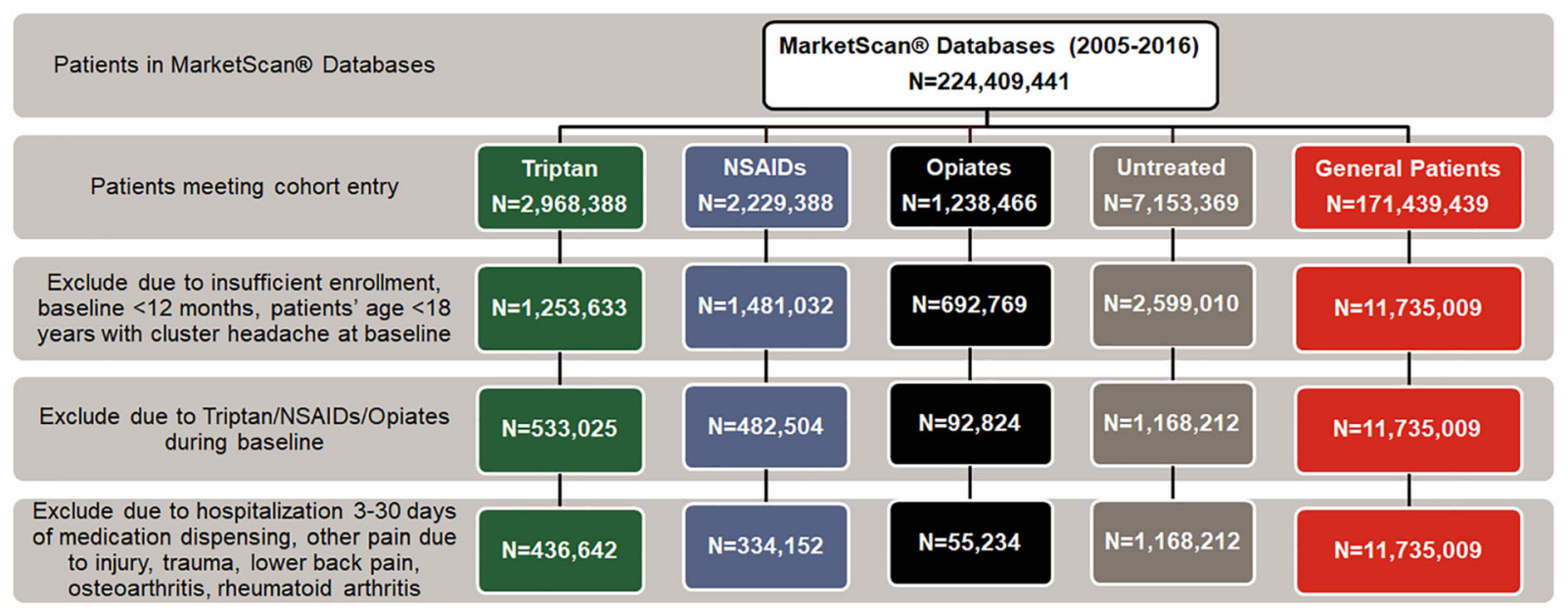

Fig. 1 Patient disposition among those identified from the IBM ${ }^{\circledR}$ MarketScan ${ }^{\circledR}$ Research Databases between January 2005 and December 2016. NSAIDs Nonsteroidal anti-inflammatory drugs

30 days or in the last $31-365$ days prior to baseline, respectively.

Select concomitant medications at baseline are displayed in Fig. 2. Among the treatment cohorts (i.e., triptan, NSAID, and opiate), patients who received triptans had fewer prescriptions for concomitant medications at baseline than did patients treated with NSAIDs or opiates. Similarly, patients in the triptan cohort had fewer cardiovascular risk factors at baseline than those in other treatment cohorts (Fig. 3).

The probability distribution of the cardiovascular DRS stratified by age is given in Fig. 4 . In this study, most of the patients had a $<0.5 \%$ risk for MI (80.8\% NSAID, $83.1 \%$ opiate, $88.9 \%$ triptan, $78.3 \%$ general nonmigraine, and $79.3 \%$ untreated migraine). Within the population in the highest risk category for MI at 1 year, a numerical difference across treatment groups was observed. A greater proportion of patients in the NSAID (4.2\%) and opiate (3.5\%) cohorts compared to the triptan (1.3\%) cohort was in the highest risk category for MI at 1 year (> 10\%).

\section{DISCUSSION}

The results of this study reveal that triptanprescribed patients with migraine were numerically younger, had fewer baseline hospitalizations and cardiovascular risk factors (e.g., hypertension, diabetes, hyperlipidemia), and had lower concomitant medication use than patients in the other treatment cohorts. Specifically, patients in the triptan cohort had fewer cardiovascular risk factors than those in the other treatment cohorts; also, a greater proportion of patients in the NSAID (4.2\%) and opiate $(3.5 \%)$ cohorts compared to those in the triptan $(1.3 \%)$ cohort were in the highest risk category for MI at 1 year (>10\%). Alternative treatment options for patients with acute migraine have been lacking for at least a decade, until recent approvals of new class medications (i.e., lasmiditan, ubrogepant). However, a large proportion of migraine patients are still treated with NSAIDs, which may be insufficiently effective, or with opiates, which carry a great risk of addiction. These results are consistent with the hypothesis that prescribers are less likely to prescribe triptans than either opioids or prescription NSAIDs to migraine patients at a greater cardiovascular risk, as the majority of healthcare providers/prescribers understand and follow the contraindications of the prescribing information from product labels [10]. It is recommended that triptan-naïve patients with multiple cardiovascular risk factors (e.g., increased age, diabetes mellitus, hypertension, smoking, obesity, strong family history of 
Table 1 Baseline demographics of inpatients identified from the IBM ${ }^{\circledR}$ MarketScan ${ }^{\circledR}$ Research Databases between January 2005 and December 2016

\begin{tabular}{|c|c|c|c|c|c|}
\hline \multirow[t]{2}{*}{ Variable $^{a}$} & \multicolumn{5}{|l|}{ Study cohorts ${ }^{b}$} \\
\hline & $\begin{array}{l}\text { Triptan } \\
(N=436,642)\end{array}$ & $\begin{array}{l}\text { NSAID } \\
(N=334,152)\end{array}$ & $\begin{array}{l}\text { Opiate } \\
(N=55,234)\end{array}$ & $\begin{array}{l}\text { Untreated migraine } \\
(N=1,168,212)\end{array}$ & $\begin{array}{l}\text { General nonmigraine } \\
(N=11,735,009)^{c}\end{array}$ \\
\hline Age, years, mean (SD) & $37.7(12.4)$ & $39.4(14.0)$ & $39.7(13.4)$ & $41.0(14.6)$ & $45.7(17.4)$ \\
\hline \multicolumn{6}{|l|}{ Gender } \\
\hline Female & $346,306(79.3)$ & $266,087(79.6)$ & $44,751(81.0)$ & $890,744(76.3)$ & $5,491,517(46.8)$ \\
\hline Migraine at baseline & $150,136(34.4)$ & $334,152(100)$ & $55,234(100)$ & $25,646(2.2)$ & $0(0.0)$ \\
\hline \multicolumn{6}{|l|}{ Insurance type } \\
\hline Commercial claims & $404,419(92.6)$ & $281,473(84.2)$ & $47,379(85.8)$ & $1,028,623(88.1)$ & $9,385,586(80.0)$ \\
\hline $\begin{array}{l}\text { Hospitalizations in last } \\
30 \text { days }\end{array}$ & $1634(0.4)$ & $27,135(8.1)$ & $7611(13.8)$ & $12,130(1.0)$ & $36,375(0.3)$ \\
\hline $\begin{array}{l}\text { Hospitalizations in last } \\
31-365 \text { days }\end{array}$ & $10,854(2.5)$ & $13,349(4.0)$ & $2363(4.3)$ & $45,349(3.9)$ & $339,158(2.9)$ \\
\hline $\begin{array}{l}\text { Emergency room visits } \\
\text { in last } 30 \text { days }\end{array}$ & $20,845(4.8)$ & $27,529(8.2)$ & $17,518(31.7)$ & $64,824(5.6)$ & $61,918(0.5)$ \\
\hline $\begin{array}{l}\text { Emergency room visits } \\
\text { in last } 31-365 \text { days }\end{array}$ & $56,244(12.9)$ & $75,821(22.7)$ & $12,518(22.7)$ & $196,742(16.8)$ & $747,700(6.4)$ \\
\hline Depression & $47,721(10.9)$ & $42,901(12.8)$ & $8800(15.9)$ & $130,811(11.2)$ & $310,857(2.7)$ \\
\hline Asthma or COPD & $29,545(6.8)$ & $32,258(9.7)$ & $6572(11.9)$ & $97,140(8.3)$ & $422,516(3.6)$ \\
\hline Anxiety & $39,814(9.1)$ & $37,311(11.2)$ & $7301(13.2)$ & $114,117(9.8)$ & $165,436(1.4)$ \\
\hline Fibromyalgia & $6986(1.6)$ & $8065(2.4)$ & $1600(2.9)$ & $39,263(3.4)$ & $62,985(0.5)$ \\
\hline
\end{tabular}

COPD Chronic obstructive pulmonary disease, NSAID nonsteroidal anti-inflammatory drug, $S D$ standard deviation

a All variables are presented as a number $(n)$ with the percentage in parenthesis unless otherwise specified

b Details on each study cohort are given in section "Cohort Formation"

${ }^{c}$ Patients in this cohort were matched to patients in the untreated migraine cohort with a 1:4 ratio based on age and sex

coronary artery disease) should receive a cardiovascular evaluation before starting triptan therapy. If such patients have a negative cardiovascular evaluation, then physicians should consider administering the first triptan dose in a medically supervised setting and performing an electrocardiogram immediately after administration [10].

It is important to note the large proportion of people with migraine in whom triptans are contraindicated due to CVD issues. According to the American Migraine Prevalence and
Prevention (AMPP) survey, $13.1 \%$ of patients with episodic migraine in the U.S. population cannot take triptans based on having at least one cardiovascular event, condition, and/or procedure [12]. This prevalence was found to increase with age (up to $25.2 \%$ in patients $\geq 60$ years old) and was higher in men than in women (13.3 vs. $11.4 \%)$. In terms of cardiovascular risk factors, data from the internet-based survey International Burden of Migraine Study (IBMS) reveal that vascular disease risk factors were present in a large proportion of patients 


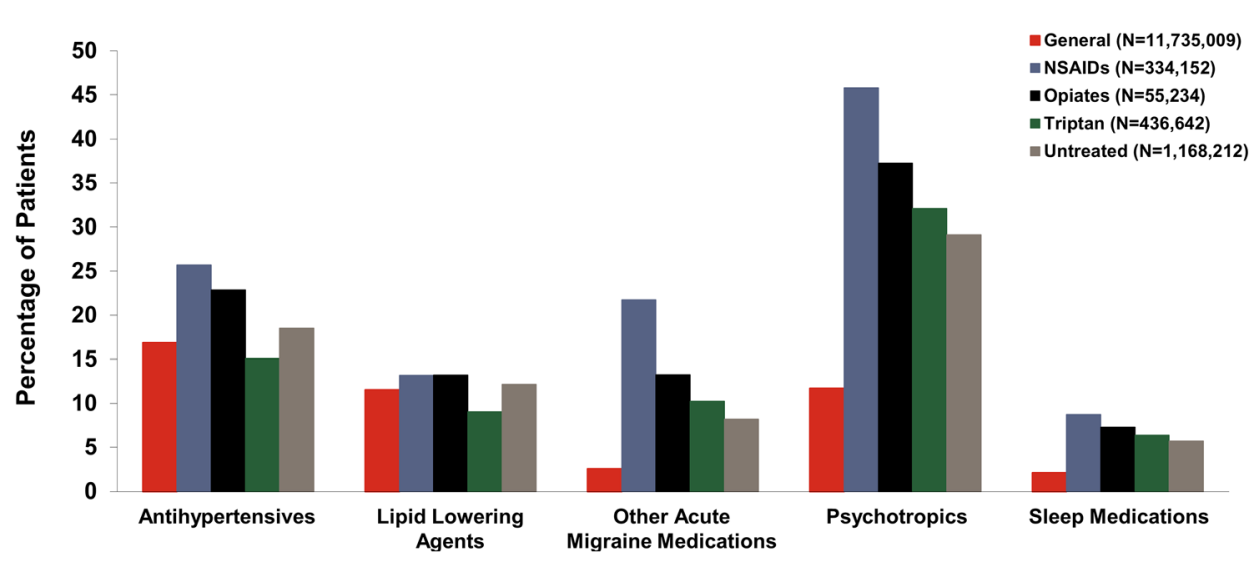

Fig. 2 Frequency of select concomitant medications at baseline according to cohort group in a retrospective cohort study of 223,023,828 patients identified from the IBM ${ }^{\circledR}$ MarketScan ${ }^{\circledR}$ Research Databases between January
2005 to December 2016 with the aim to examine the impact of cardiovascular risk factors on triptan prescribing patterns for migraine in a real-world setting. Details on each study cohort are given in section "Cohort Formation"

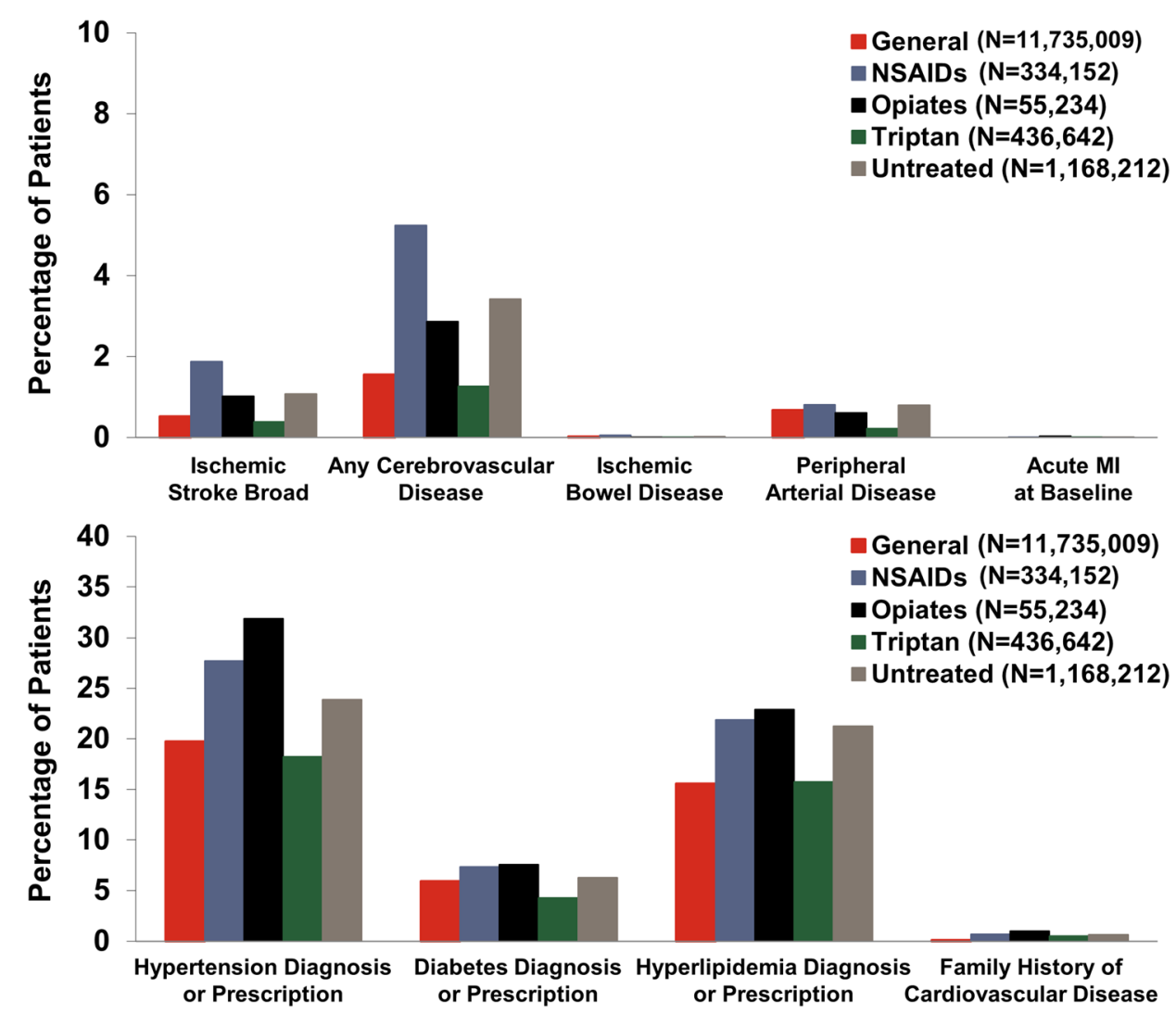

Fig. 3 Incidence of cardiovascular risk factors at baseline according to cohort group in patients identified from the IBM ${ }^{\circledR}$ MarketScan ${ }^{\circledR}$ Research Databases between January 2005 and December 2016. MI Myocardial infarction

with migraine: $208(41.7 \%)$ patients with chronic migraine and 2739 (33.3\%) patients with episodic migraine $(P=0.0005)$ [13]. The AMPP study estimated that there are 2.6 million 

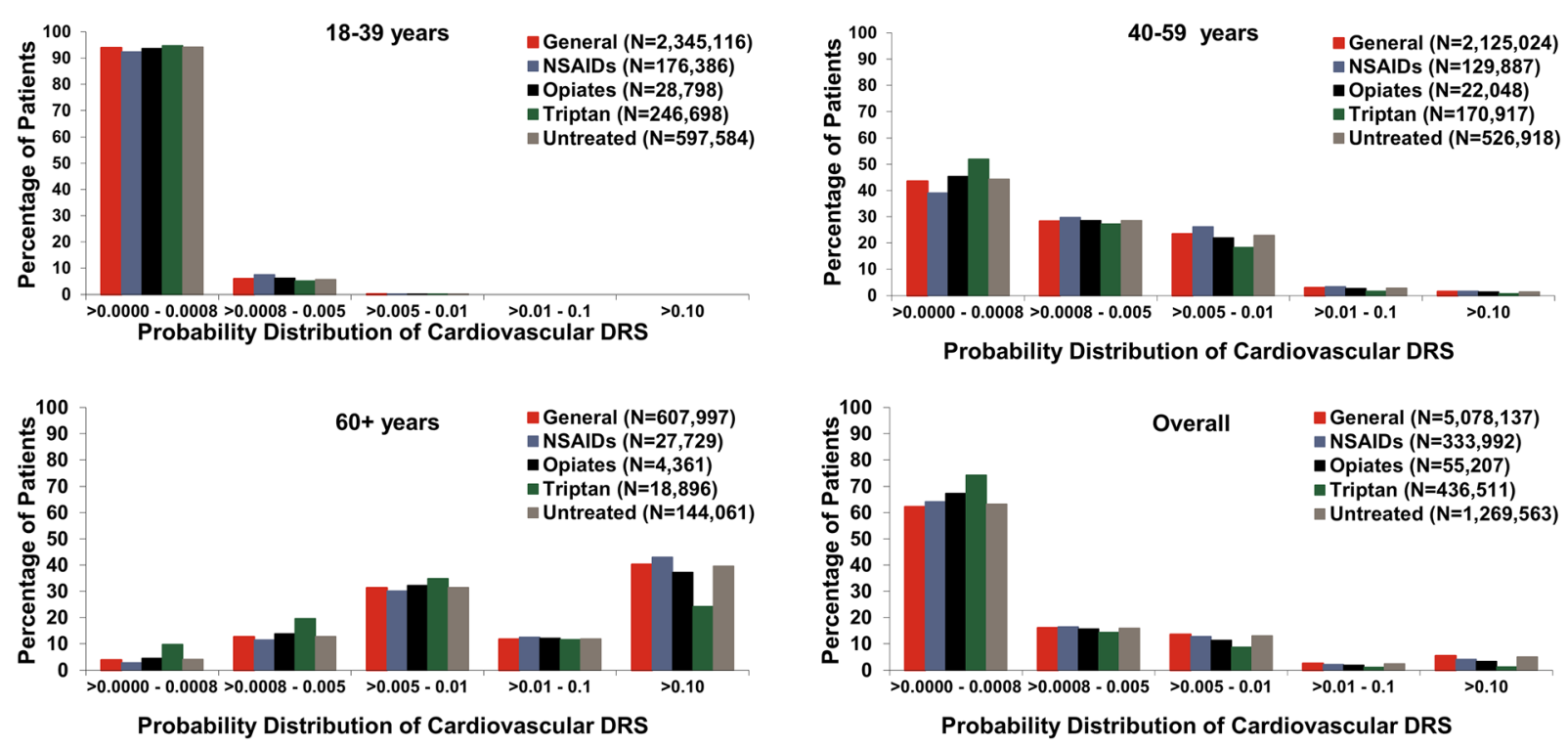

Fig. 4 Probability distribution of the cardiovascular disease risk score $(D R S)$ stratified by age and overall in patients identified from the IBM ${ }^{\circledR}$ MarketScan ${ }^{\circledR}$ Research Databases between January 2005 and December 2016 by age groups

people with episodic migraine in the USA, among all of whom triptans are contraindicated due to cardiovascular events, conditions, and procedures [12]. These numbers do not include patients with chronic migraine who likely have an even higher rate of cardiovascular issues.

Our findings are consistent with those of previous studies that showed the presence of cardiovascular risk factors was associated with a lower rate of triptan use. A retrospective crosssectional study showed that the proportion of patients with migraine using triptans was lower among those with cardiovascular risk factors than among those without (18.1 vs. $25.5 \%)$ [14]. After controlling for demographics, socioeconomic status, access to care, and health status, patients with migraine without cardiovascular risk factors were more likely to use triptans versus patients with migraine with one CVD risk factor (adjusted odds ratio 1.83; 95\% confidence interval 1.17-2.87) [14]. Buse et al. [12] state that periodic cardiovascular evaluation is recommended because cardiovascular risk increases with age.

Although several studies provide conflicting results regarding the safety of triptans, experts do believe that their effectiveness indicates they should be considered as a treatment option for all individuals with migraine because there are no other acute migraine medications that are safe to prescribe to migraine patients with cardiovascular risk factors [15]. For example, the U.S. Food and Drug Administration issued warnings regarding the association of NSAIDs and increased risk of heart attack and stroke, and a study published in 2016 [16] reported that prescription opiates can increase the risk of coronary heart disease and cardiovascular death. These factors highlight that there are clearly unmet medical needs for migraine patients with higher risk for CVD [17-25].

The strengths and limitations of this study should be noted. Two major strengths are that the study utilized a large sample containing real-world data and that it was representative of the commercially insured USA-based population. The limitations of the study are that it was a descriptive analysis and thus no formal statistical tests were performed to compare results across different study cohorts. In addition, as with all other observational studies, the data were electronically captured and not originally composed for research purposes. Since over-thecounter analgesics and NSAIDs could not be assessed in the study, it was possible for the untreated migraine cohort to contain a 
percentage of patients whose migraine was treated with such agents. Lastly, the data should be interpreted in the context of the following: (1) lack of clinical detail, (2) ingestion of prescription was unknown, (3) important confounding details (e.g., life-style factors, such as smoking, alcohol use, body mass index) were missing.

\section{CONCLUSION}

Patients with migraine who had more cardiovascular risk factors and a higher 1-year MI risk were disproportionately prescribed opiates and NSAIDs compared to triptans. These findings reflect the standard care and treatment patterns for patients with contraindications for triptans. Future research should explore the unmet needs for patients with migraine and disorders for which triptan therapy is contraindicated.

\section{ACKNOWLEDGEMENTS}

Funding. Sponsorship for this study and the journal's Rapid Service Fee were provided by Eli Lilly and Company (Indianapolis, USA).

Medical Writing and Editorial Assistance. Medical writing support was provided by Aric Fader, PhD, CMPP and Regina E. Burris, $\mathrm{PhD}$, and editorial support was provided by Angela Lorio, ELS of Syneos Health, and funded by Eli Lilly and Company in accordance with Good Publication Practice (GPP3) guidelines (https://www.ismpp.org/gpp3).

Authorship. All named authors meet the International Committee of Medical Journal Editors (ICMJE) criteria for authorship for this article, take responsibility for the integrity of the work as a whole, and have given their approval for this version to be published.

Prior Presentation. Parts of this article were previously presented as a poster presentation at the AAN 71st Annual Meeting, May 4-10, 2019, Philadelphia, PA. The abstract for this presentation is cited as follows: $\mathrm{Hu} \mathrm{Li}$, Maurice Vincent, Xiang Zhang, Robert Goodloe, Sheena Aurora. Acute Anti-Migraine Prescription Varies According to Baseline Cardiovascular Risk and Clinical Characteristics: A Real-World Evidence Study (P4.10-017). Neurology Apr 2019, 92 (15 Supplement) P4.10-017.

Disclosures. $\mathrm{Hu} \mathrm{Li}$, Maurice Vincent, Ellen B. Dennehy, and Robert Goodloe are full-time employees of Eli Lilly and Company, Indianapolis, IN, USA, and are minority holders of company stock. At the time the study was conducted, Xiang Zhang and Sheena Aurora were full-time employees of Eli Lilly and Company, Indianapolis, IN, USA, and were minority holders of company stock. Xiang Zhang is currently affiliated with CSL Behring (King of Prussia, PA, USA). Sheena Aurora is currently affiliated with Impel NeuroPharma (Seattle, WA, USA). Ellen B. Dennehy is an adjunct member of the faculty of the Department of Psychological Sciences, Purdue University, West Lafayette, IN, USA, but receives no compensation or other benefits from Purdue. Timothy R. Smith is an employee of StudyMetrix Research, St Peters, MO, USA.

Compliance with Ethics Guidelines. This article is based on a retrospective analysis of deidentified patient data from the United States healthcare system, and does not contain any studies with human participants or animals performed by any of the authors.

Data Availability. Eli Lilly and Company provides access to all individual participant data collected during the trial, after anonymization, with the exception of pharmacokinetic or genetic data. Data are available to request 6 months after the indication studied has been approved in the USA and EU and after primary publication acceptance, whichever is later. No expiration date of data requests is currently set once data are made available. Access is provided after a proposal has been approved by an independent review committee identified for this purpose and after receipt of a signed data sharing agreement. Data and documents, including the study protocol, statistical analysis plan, 
clinical study report, blank or annotated case report forms, will be provided in a secure data sharing environment. For details on submitting a request, see the instructions provided at www. vivli.org.

Open Access. This article is licensed under a Creative Commons Attribution-NonCommercial 4.0 International License, which permits any non-commercial use, sharing, adaptation, distribution and reproduction in any medium or format, as long as you give appropriate credit to the original author(s) and the source, provide a link to the Creative Commons licence, and indicate if changes were made. The images or other third party material in this article are included in the article's Creative Commons licence, unless indicated otherwise in a credit line to the material. If material is not included in the article's Creative Commons licence and your intended use is not permitted by statutory regulation or exceeds the permitted use, you will need to obtain permission directly from the copyright holder. To view a copy of this licence, visit http://creativecommons.org/licenses/by$\mathrm{nc} / 4.0 /$.

\section{REFERENCES}

1. Steiner TJ, Stovner LJ, Birbeck GL. Migraine: the seventh disabler. J Headache Pain. 2013;14:1. https://doi.org/10.1186/1129-2377-14-1.

2. Etminan M, Takkouche B, Isorna FC, Samii A. Risk of ischaemic stroke in people with migraine: systematic review and meta-analysis of observational studies. BMJ. 2005;330(7482):63. https://doi.org/ 10.1136/bmj.38302.504063.8F.

3. Schurks M, Rist PM, Bigal ME, Buring JE, Lipton RB, Kurth T. Migraine and cardiovascular disease: systematic review and meta-analysis. BMJ. 2009;339: b3914. https://doi.org/10.1136/bmj.b3914.

4. Mahmoud AN, Mentias A, Elgendy AY, et al. Migraine and the risk of cardiovascular and cerebrovascular events: a meta-analysis of 16 cohort studies including 1,152,407 subjects. BMJ Open. 2018;8(3):e020498. bmjopen-2017-020498.
5. Kurth T, Winter AC, Eliassen AH, et al. Migraine and risk of cardiovascular disease in women: prospective cohort study. BMJ. 2016;353:i2610. https://doi.org/10.1136/bmj.i2610.

6. Marmura MJ, Silberstein SD, Schwedt TJ. The acute treatment of migraine in adults: the American Headache Society evidence assessment of migraine pharmacotherapies. Headache. 2015;55(1):3-20. https://doi.org/10.1111/head.12499.

7. Ferrari MD, Roon KI, Lipton RB, Goadsby PJ. Oral triptans (serotonin 5-ht(1b/1d) agonists) in acute migraine treatment: a meta-analysis of 53 trials. Lancet. 2001;358(9294):1668-755. https://doi.org/ 10.1016/S0140-6736(01)06711-3.

8. Roberto G, Raschi E, Piccinni C, et al. Adverse cardiovascular events associated with triptans and ergotamines for treatment of migraine: systematic review of observational studies. Cephalalgia. 2015;35(2):118-31. 0333102414550416 .

9. Gelfand AA, Goadsby PJ. A neurologist's guide to acute migraine therapy in the emergency room. Neurohospitalist. 2012;2(2):51-9. https://doi.org/ $10.1177 / 1941874412439583$.

10. GlaxoSmithKline (GSK). Imitrex (sumatriptan succinate) tablets [full prescribing information]. Research Triangle Park, NC: GSK; 2017.

11. Bigal ME, Golden W, Buse D, Chen YT, Lipton RB. Triptan use as a function of cardiovascular risk. A population-based study. Headache. 2010;50(2): 256-63. https://doi.org/10.1111/j.1526-4610.2009. 01595.x.

12. Buse DC, Reed ML, Fanning KM, Kurth T, Lipton RB. Cardiovascular events, conditions, and procedures among people with episodic migraine in the US population: results from the American Migraine Prevalence and Prevention (AMPP) study. Headache. 2017;57(1):31-44. https://doi.org/10.1111/ head.12962.

13. Blumenfeld AM, Varon SF, Wilcox TK, et al. Disability, HRQoL and resource use among chronic and episodic migraineurs: results from the International Burden of Migraine Study (IBMS). Cephalalgia. 2011;31(3):301-15. https://doi.org/10.1177/ 0333102410381145 .

14. Alwhaibi M, Deb A, Sambamoorthi U. Triptans use for migraine headache among nonelderly adults with cardiovascular risk. Pain Res Treat. 2016;2016: 8538101. https://doi.org/10.1155/2016/8538101.

15. Gryglas A, Smigiel R. Migraine and stroke: what's the link? What to do? Curr Neurol Neurosci Rep. 
2017;17(3):22. https://doi.org/10.1007/s11910-0170729-y.

16. Khodneva Y, Muntner P, Kertesz S, Kissela B, Safford MM. Prescription opioid use and risk of coronary heart disease, stroke, and cardiovascular death among adults from a prospective cohort (regards study). Pain Med. 2016;17(3):444-55. https://doi. org/10.1111/pme.12916.

17. Bigal ME, Kurth $\mathrm{T}, \mathrm{Hu} \mathrm{H}$, Santanello N, Lipton RB. Migraine and cardiovascular disease: possible mechanisms of interaction. Neurology. 2009;72(21):1864-71. https://doi.org/10.1212/ WNL.0b013e3181a71220.

18. Trelle S, Reichenbach S, Wandel S, et al. Cardiovascular safety of non-steroidal anti-inflammatory drugs: network meta-analysis. BMJ. 2011;342: c7086. https://doi.org/10.1136/bmj.c7086.

19. Tietjen GE. Migraine as a systemic vasculopathy. Cephalalgia. 2009;29(9):987-96. https://doi.org/10. 1111/j.1468-2982.2009.01937.x.

20. Lee ST, Chu K, Jung KH, et al. Decreased number and function of endothelial progenitor cells in patients with migraine. Neurology. 2008;70(17):
$1510-7$. 0000294329.93565 .94 .

https://doi.org/10.1212/01.wnl.

21. Jesurum JT, Fuller CJ, Murinova N, Truva CM, Lucas SM. Aspirin's effect on platelet inhibition in migraineurs. Headache. 2012;52(8):1207-18. https://doi.org/10.1111/j.1526-4610.2012.02143.x.

22. Vanmolkot FH, Van Bortel LM, de Hoon JN. Altered arterial function in migraine of recent onset. Neurology. 2007;68(19):1563-70. https://doi.org/10. 1212/01.wnl.0000260964.28393.ed.

23. Schwerzmann M, Nedeltchev $K$, Lagger $F$, et al. Prevalence and size of directly detected patent foramen ovale in migraine with aura. Neurology. 2005;65(9):1415-8. https://doi.org/10.1212/01.wnl. 0000179800.73706 .20 .

24. Dreier JP, Reiffurth C. The stroke-migraine depolarization continuum. Neuron. 2015;86(4):902-22. https://doi.org/10.1016/j.neuron.2015.04.004.

25. Eikermann-Haerter K, Lee JH, Yuzawa I, et al. Migraine mutations increase stroke vulnerability by facilitating ischemic depolarizations. Circulation. 2012;125(2):335-45. https://doi.org/10.1161/ CIRCULATIONAHA.111.045096. 